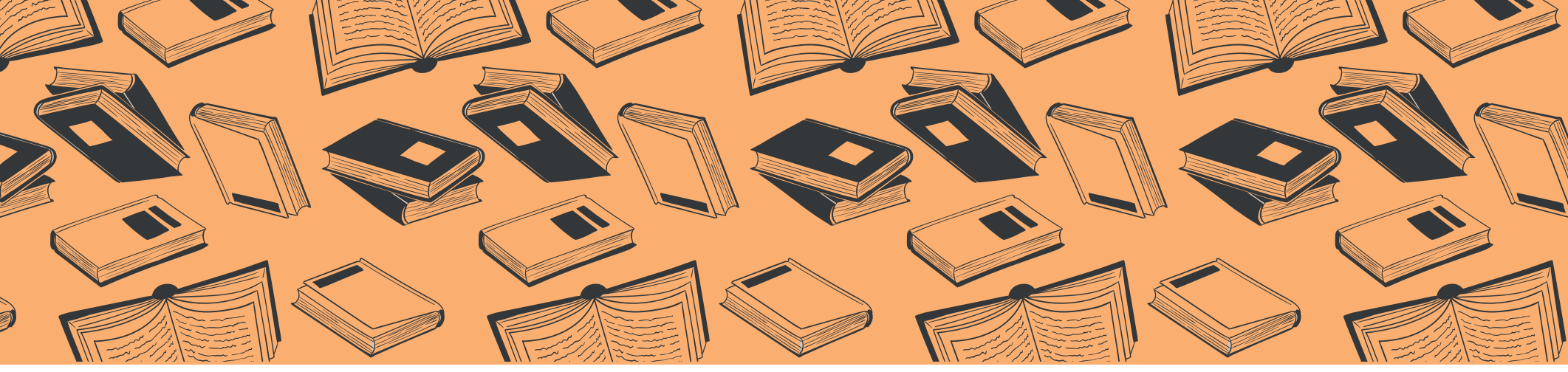

\section{Una cita con el libro antiguo en Colombia ${ }^{1}$}

Por Natalia Pérez Peña ${ }^{2}$

1 Este trabajo es producto de la investigación Descripción y análisis del libro antiguo en la comunidad de los Padres Dominicos.

2 Magíster en semiótica de la Universidad Jorge Tadeo Lozano. Diseñadora gráfica de la Universidad de Boyacá. Docente Facultad de Diseño Gráfico. Correo electrónico: natalia.perez@usantotomas.edu.co esde el Diseño Gráfico, inspirados en la preocupación por el patrimonio gráfico - concepto en el que se ubica la producción bibliográfica-, y considerando la participación del Archivo Histórico de la Provincia de San Luís Bertrán de Colombia, habitado por cartas, folios y libros de profundo valor para la Orden de Predicadores y para la historia de la humanidad, se pretende describir grosso modo, a través de este texto, el contexto y desarrollo conceptual que orienta un estudio sobre el libro antiguo.

El libro en tanto testimonio y objeto de valor histórico y por consiguiente textual, debe entenderse como documento patrimonial (García, 2008), debido a ello, los estudios sobre su caracterización, usos, producción e historia han de ser razones fundamentales para comprender la evolución del Diseño Gráfico. Por su parte, el libro antiguo, vinculado a la impresión de caracteres alfabéticos a través del uso de piezas de metal intercambiables, conocida como la imprenta de tipos móviles o la impresión tipográfica, se desarrollará ampliamente a partir de este avance tecnológico que favoreció la difusión del conocimiento y la producción masiva de textos.

Es importante señalar que, el libro antiguo se constituye en una herramienta histórica que permite leer las condiciones o características de un contexto particular. Así lo reflejan países como Argentina, Brasil, Cuba, Guatemala, entre otros, en donde el fondo bibliográfico, las obras raras, los fondos raros y valiosos (García, 2011), manifiestan un interés especial por rescatar, describir y catalogar los libros que por sus condiciones y momento de producción hacen parte de este grupo, pues a través de ellos se accede a una porción importante de la realidad histórica de un país. 


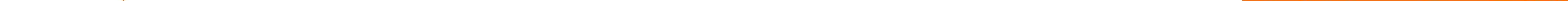


a otro tiempo. El orden preciso determinado por la jerarquización de textos que a través del puntaje de la letra refleja el cuidado y precisión de las portadas de estos libros. La conciencia plena de la disposición en dos columnas que aseguraba un patrón articulado a los reclamos - presencia de las primeras letras de la palabra con que inicia la siguiente página-. Las capitales y capitulares que fungen como ilustraciones al recrear escenas o, en su defecto, elementos ornamentales una u otra, acompañan permanentemente cada libro. Por supuesto, las gráficas con que de manera concreta se ilustra el tema desarrollado por cada libro. Todas estas características son solo una parte de la cantidad y diversidad de componentes que conserva el libro antiguo y son la invitación para continuar trabajando en el reconocimiento de la producción bibliográfica a través de su tipología, elementos compositivos, anatomía, ornamentación, caracterización tipográfica, cualidades ilustrativas, etc.; puesto que con ello se reafirma la necesidad de difundir un patrimonio que no sólo refleja la historia del producto en sí mismo, sino que permite reconocer las condiciones de un contexto, la evolución histórica del libro y por ende, la del ser humano.

Finalmente, estas cavilaciones se reflejan en las figuras 1, 2 y 3 como parte del registro desarrollado en el proyecto de investigación Descripción y análisis del libro antiguo en la comunidad de los Padres Dominicos.

Figura 1. Metalogica Disputationes

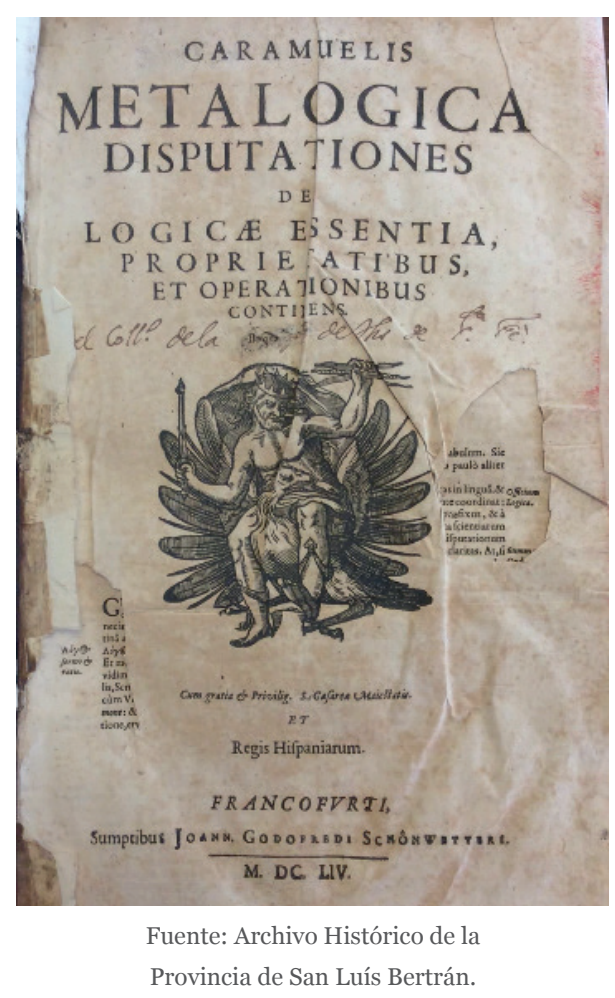


Figura 2. Fragmento del libro Divi Thomae Aqvinatis Doctoris Angelici

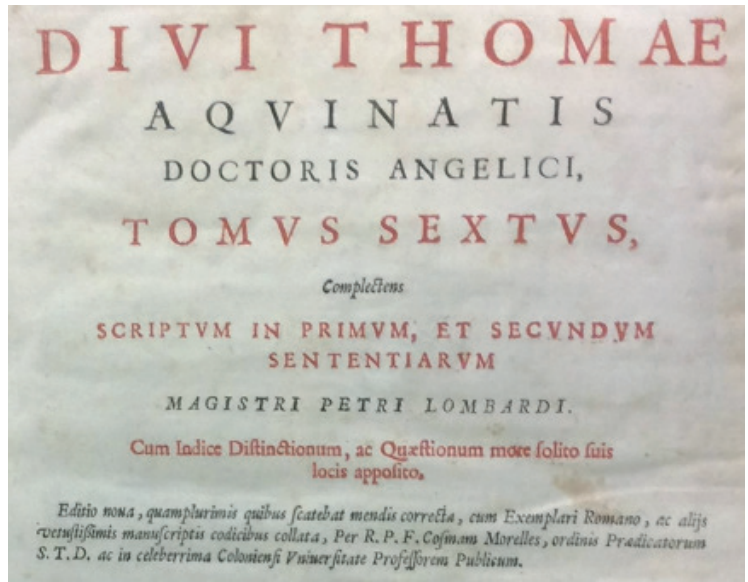

Fuente: Archivo Histórico de la Provincia de San Luís Bertrán.

Figura 3. Glorias de la Virgen

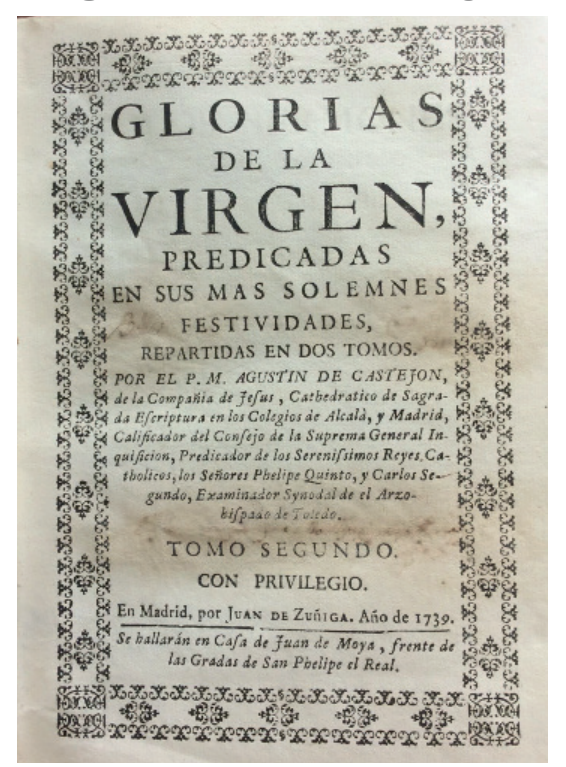

Fuente: Biblioteca del convento Santo Domingo, Tunja.

\section{Referencias}

García, I. (2011). Secretos del estante. Elementos para la descripción bibliográfica del libro antiguo. México: Universidad Autónoma de México.

Garone, M. (2012). Fuentes para el estudio de la tipografía, la imprenta y el libro antiguo mexicano (1539-1821). Pecia Complutense, 9(17), 59-84. Madrid: Universidad Complutense de Madrid.

Pedraza, J.M., (2003). El libro antiguo $1^{a}$ edición. Madrid: Síntesis.

Villagómez, C. (2014). Elementos del libro antiguo y su reutilización en el diseño gráfico actual. Revista Interiorgráfico, 14. Recuperado de https://www.interiorgrafico.com/edicion/decimo-cuarta-edicion-octubre-2014/elementos-del-libro-antiguo-y-su-reutilizacion-e n-el-diseno-grafico-actual 